\title{
In situ alloying: investigation of the melt pool stability during powder bed fusion of metals using a laser beam in a novel experimental set-up
}

\author{
Andreas Wimmer $^{1}\left[\right.$ [ $\cdot$ Fabian Hofstaetter $^{1} \cdot$ Constantin Jugert $^{1} \cdot$ Katrin Wudy $^{2} \cdot$ Michael F. Zaeh $^{1}$
}

Received: 27 June 2021 / Accepted: 17 October 2021 / Published online: 31 October 2021

(c) The Author(s) 2021

\begin{abstract}
The limited access to materials for the Powder Bed Fusion of Metals using a Laser Beam (PBF-LB/M) is compensated by in situ alloying. Individual melt pool characteristics can be specifically influenced to improve the mechanical properties of the final part. However, conventional PBF-LB/M machines allow only limited access for detailed observation of the process zone and, in particular, the melt pool. This paper presents a methodology for systematically analyzing the melt pool in the cross section to determine the in situ variation of the melt pool depth. A custom PBF-LB/M test bench was devised to enable investigation of the process zone using high-speed infrared cameras. The image data were processed automatically using a dedicated algorithm. The methodology was applied to analyze the effect of additives on the melt pool stability. Stainless steel $316 \mathrm{~L}$ powder was blended with the aluminum alloy AlSi10Mg by up to $20 \mathrm{wt} . \%$. It was found that the blended powder significantly reduced the variation of the melt pool depth.
\end{abstract}

Keywords Additive manufacturing · Powder bed fusion of metals using a laser beam (PBF-LB/M) $\cdot$ Melt pool $\cdot$ Process monitoring $\cdot$ In situ alloying

\section{Introduction and state of the art}

Powder Bed Fusion of Metals using a Laser Beam (PBF$\mathrm{LB} / \mathrm{M})$ enables the production of geometrically complex parts [1]. In the PBF-LB/M process, a laser irradiates the cross section of a component in a powder layer. Initially adapted to rapid prototyping only, it is now reaching a level of maturity that allows large-scale production. This emerging technology provides new opportunities in the fields of metallurgy, material science, and production. However, there are several risks and drawbacks that need to be addressed [2]. To fulfill the needs of upcoming PBF-LB/M applications, it is inevitable that special alloys will be required. Most materials used in the PBF-LB/M process were created and optimized for casting or forging operations, in which

Andreas Wimmer

andreas.wimmer@iwb.tum.de

1 Technical University of Munich, Institute for Machine Tools and Industrial Management, Boltzmannstr. 15, 85748 Garching, Germany

2 Technical University of Munich, Professorship for Laser-based Additive Manufacturing, Boltzmannstr. 15, 85748 Garching, Germany they form a fine, homogeneous microstructure. In contrast, PBF-LB/M is characterized by periodic heating and cooling, which is likely to cause a metastable microstructure [3]. This can lead to defects, such as porosity and hot cracks, which reduce the final part strength [4]. Martin et al. [5] and Zhao et al. [6] found a coherence between the formation of porosity associated with melt pool instabilities, which presumes that a more stable melt pool results in a higher part strength. Research into alloys that are specifically optimized for PBF$\mathrm{LB} / \mathrm{M}$ is, therefore, crucially needed. In addition to avoiding defects, mechanical properties can also be improved by changing the alloy composition. By adjusting the solidification path via the alloy composition, tailored microstructures are possible.

Various approaches to modifying available alloys can be found in literature. These involve either the blending of additives to already existing alloys or the use of pre-alloyed atomized powders.

Fischer et al. [7] found the former method to be successful in mechanical engineering contexts. Even material combinations with very different melting temperatures revealed acceptable chemical homogeneity.

Montero-Sistiaga et al. [8] detected strong microcrack formation in the aluminum alloy 7075, a wrought alloy of 
high strength. The addition of $3 \mathrm{wt} . \%$ and $4 \mathrm{wt} . \%$ of silicon to the base powder by mechanical mixing resulted not only in increased density but also in a reduction in microcracks, due to grain refinement.

Martin et al. [9] integrated zirconium nanoparticles into the aluminum alloys 7075 and 6061 . The purpose of the particles was to control solidification during the PBF$\mathrm{LB} / \mathrm{M}$ process, to obtain fine-grained, equiaxed microstructures. The parts obtained were without cracks, as an equiaxed structure more easily accommodates strains due to the thermally induced shrinkage.

Several studies have been conducted with the aim of improving the yield strength of stainless steel 316L by adding TiC nanoparticles to the powder. Zhai et al. [10] and Almangour et al. [11] demonstrated a significant increase in both yield strength and mechanical properties. The authors of [12] discovered, that the yield strength of stainless steel 316L can be improved by adding $1 \mathrm{wt} . \%$ and 3 wt.\% of TiC nanoparticles. Furthermore, the grain size was refined as a result of the added particles.

Wimmer et al. [13] blended stainless steel 316L powder with the aluminum alloy AlSi10Mg. They found that the cooling rate of the molten track could be significantly altered by adding the aluminum alloy AlSi10Mg.

The following influencing factors need to be considered when choosing an alloy or element to be used as an additive: melt pool stability, resulting microstructure, temperature profile and affinity for certain defects. The additives can cause different local modifications in the melt pool, depending on their thermodynamic and physical properties, which can lead to differences in the melt pool characteristics. Also, considering the surface tension properties of the alloy used, influences due to Marangoni convection and, therefore, on the stability and shape of the melt pool can be caused [14].

Investigating the influence of powder additives on melt pool behavior requires the use of specialized observation techniques for the process zone. At a certain viewing angle, the geometry of the process zone can be observed, which enables an analysis of the melt pool's stability. In PBF$\mathrm{LB} / \mathrm{M}$, the most relevant geometric information in the context of melt pool stability is derived from the cross-sectional view. The melt pool depth can be readily extracted from ex situ investigations of the microsection, but this only provides information about the total depth of the melt, and not the dynamic depth or shape of the depression. In addition, a significant experimental effort is required to obtain meaningful values and standard deviations.

Calta et al. [15] presented an instrument for performing in situ time-resolved X-ray imaging and diffraction during the PBF-LB/M process. They melted single tracks in a powder layer without taking hatching into account. The authors stated that thermal boundary conditions imposed by the glassy carbon windows may have influenced the melt pool behavior due to the large melt pool width.

This paper presents a novel alternative set-up for investigating the melt pool in the cross section, based on highspeed thermographic imaging. In addition to the melt pool geometry, thermographic imaging provides information about the temperature profiles in and around the melt pool. This can be used to determine cooling rates, validate simulation results, and investigate the energy transfer between the gas, liquid, and solid phases. The uniqueness of the set-up is demonstrated by investigations of the melt pool stability for in situ alloying. The effects on the variation of the melt pool depth were analyzed for stainless steel $316 \mathrm{~L}$ powder blended with the aluminum alloy AlSi10Mg (in the following named 316L and AlSi10Mg). According to [16], the surface tension of the AlSi10Mg is almost half that of $316 \mathrm{~L}$. Besides, the temperature dependency of the surface tension is lower for $\mathrm{AlSi} 10 \mathrm{Mg}$ than for 316L. On the one hand, the joint decrease in the surface tension and in its variation with temperature may reduce the Marangoni convection, which most probably stabilizes the melt pool. On the other hand, the low melting and vaporization point may result in the evaporation of the aluminum, promoting the formation of a keyhole and porosities.

\section{Materials and methods}

This section gives a detailed description of the powder blending, the experimental set-up, and the methodology used for determining the melt pool depth using high-speed thermographic imaging.

\subsection{Powder blending}

In the experiments, $316 \mathrm{~L}$ powder was blended with AlSi10Mg powder (Table 1) using a roller mixer (Edmund Buehler RM 2, $80 \mathrm{rpm}$ ). To do this, the powder was filled into cylindrical containers and rotated on the roller mixer for two hours to ensure a statistically homogeneous powder blend. A similar method was used in [13], where it displayed a homogeneous powder blend.

Table 1 Experimental design; a total of four experiments were performed

\begin{tabular}{lllll}
\hline Nr. & $\begin{array}{l}\text { 316L } \\
\text { in wt.\% }\end{array}$ & $\begin{array}{l}\text { AlSi10Mg } \\
\text { in wt.\% }\end{array}$ & $\begin{array}{l}\text { Laser power } \\
\text { in W }\end{array}$ & $\begin{array}{l}\text { Scan speed } \\
\text { in } \mathrm{m} / \mathrm{s}\end{array}$ \\
\hline 1 & 100 & 0 & 175 & 0.375 \\
2 & 99 & 1 & 175 & 0.375 \\
3 & 95 & 5 & 175 & 0.375 \\
4 & 80 & 20 & 175 & 0.375 \\
\hline
\end{tabular}


To maintain the focus on the influence of the powder's properties, the laser power and scanning speed were held constant.

\subsection{Experimental set-up}

The experimental set-up depicted in Fig. 1 consists of a $1000 \mathrm{~W}$ fiber laser (IPG YLR-Y14), a chiller (Termotek P300), an optical bench and a PBF-LB/M chamber. The set-up was designed to enable investigations of the PBF$\mathrm{LB} / \mathrm{M}$ process and is equipped with the same components as conventional PBF-LB/M systems.

Figure 2 shows the top view of the optical bench, which has as dust-tight enclosure. It consists of a breadboard (Thorlabs), on which several optical instruments are mounted and aligned for an open beam path. The beam is expanded by a collimator (IPG D50-F200) and is then guided through the scanning systems for area irradiation (Scanlab intelliSCAN III30) and beam waist variation (Scanlab varioSCAN de40i). The laser and the scanners are connected by a high-performance control board (RTC6) to ensure the required level of dynamic performance and accuracy. The laser is reflected by a dichroic mirror, while emissions from the process are transmitted and detected, for example by a pyrometer.

The PBF-LB/M chamber (Fig. 3) enables the process to be observed both diagonally from the top and perpendicularly to the laser beam path from the front. The latter option was used for this study. This viewing angle allows detailed analysis of the melt pool behavior in a cross-sectional view. It is also possible to observe the heat conduction in the powder bed and the solidified area by means of a thermography camera. The chamber mainly consists of milled aluminum

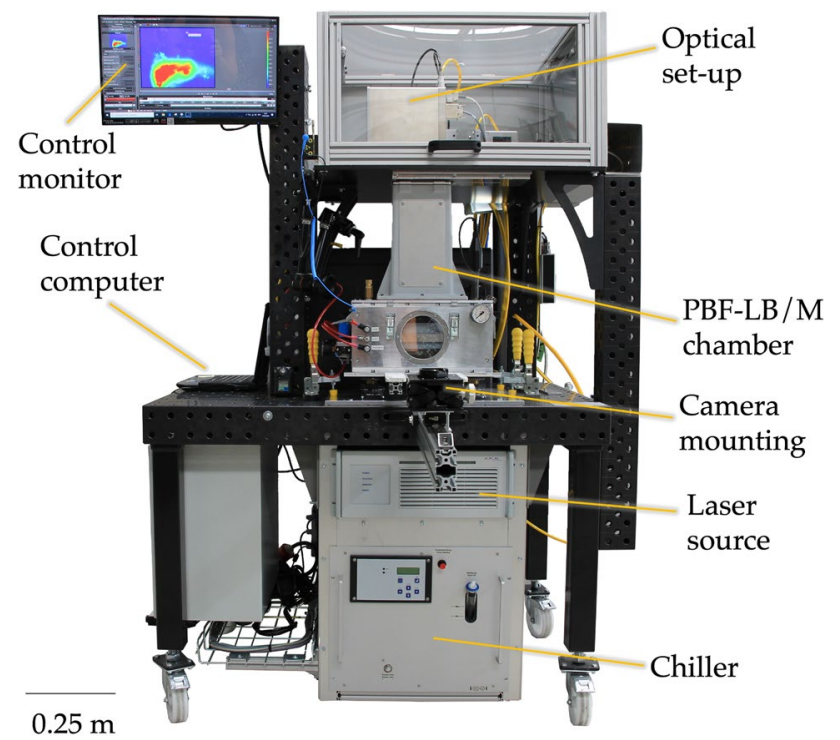

Fig. 1 Experimental set-up for process monitoring during PBF-LB/M

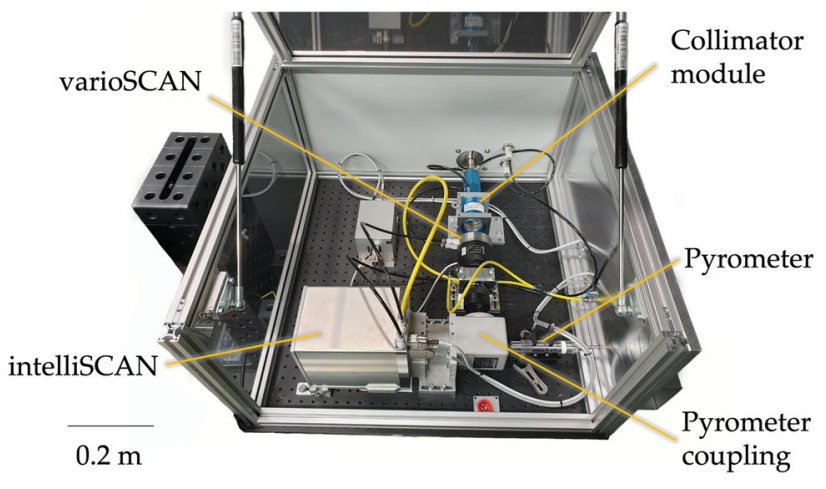

Fig. 2 Optical set-up with an open beam path allowing to deflect the beam in all three spatial directions

plates with a bent and chamfered side and back made from 1.4301 stainless steel. A plate with T-shaped grooves is located on the bottom of the chamber to ensure flexibility for mounting the interior equipment. The structure on the top was manufactured from polylactide (PLA) material by Fused Deposition Modeling (FDM). The FDM part was post-treated with a polymer primer, followed by several iterations of filling and sanding. This treatment ensures that the part is gas-tight. The laser window on the top is coated on both sides for the transmission of 1064-1076 nm wavelengths. To facilitate access to the process chamber, the top plate is clamped in place by eight quick-release fasteners. The top plate is placed on a rubber sealant to ensure that the system is gas-tight. All parts not requiring easy replacement were sealed with silicon sealant. Monitoring of the oxygen content is particularly important due to the sensitivity of the individual layers in the PBF-LB/M process to oxidation.

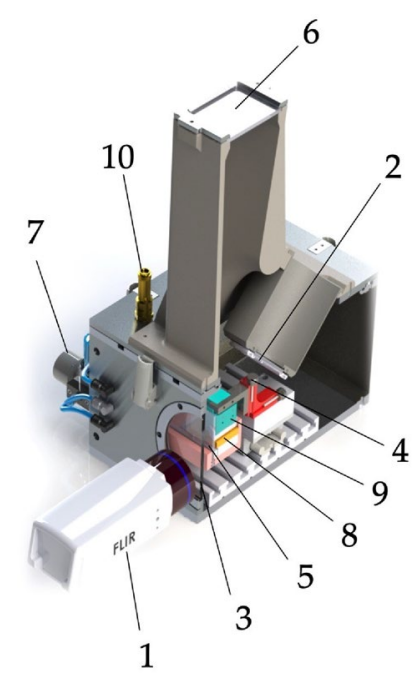

Fig. 3 Sectional view of the PBF-LB/M chamber; the various components are listed in Table 2 
The chamber is equipped with an oxygen monitoring device (Greisinger OXY 3690 MP-LO) which is able to measure the oxygen content with an accuracy of $\pm 0.1 \%$ for oxygen values of $\leq 0.2$ Vol.- $\%$.

The interior of the chamber consists primarily of a building platform, a recoater, and a system to ensure a laminar process gas flow. The recoater is guided by a high-precision linear rail and an original recoater blade from an EOS M270 machine. The recoating system has a tactile dial gauge with a resolution of $1 \mu \mathrm{m}$ and a total measuring range of $1 \mathrm{~mm}$ to enable high-precision measurement of the set layer height. In addition, the building platform carrier was supplemented by a three-point fence with a clamping unit. This improves reproducibility when the building platform is changed. For cross-sectional observation, a window (Vitron CVD zinc sulfide) was used that is translucent for IR light with wavelengths of $2-5 \mu \mathrm{m}$ to allow emissions from the process zone to be transmitted to the high-speed IR camera. To protect the zinc sulfide $(\mathrm{ZnS})$ glass from spatter, a second glass plate was positioned between the $\mathrm{ZnS}$ glass and the process zone. This means that the glass ceramic can be easily exchanged if contaminated by spatter or other process residues.

\subsection{Procedure}

This section describes the calibration procedure of the entire set-up and the methodology for evaluating the thermographic images.

\subsubsection{Transmission and emission coefficient}

The transmission spectra of the glass ceramic and the $\mathrm{ZnS}$ glass were evaluated to enable calibration of the transmission coefficient. With a spectral range of 3.0-5.0 $\mu \mathrm{m}$ (range of the lens set-up used), the $\mathrm{ZnS}$ glass has a mean transmission of $72.57 \%$ while the glass ceramic has a mean of $43.13 \%$. The combined transmission is $31.30 \%$.

The recording of the thermographic process emissions assume a constant emission coefficient. For the analysis, $\epsilon=$ 0.53 was chosen according to [17]. Due to the highly unstable emission coefficient in and around the phase transition, the evaluation of the melt pool geometry was carried out according to [18]. The melt pool geometry was therefore measured with no dependency on the emission coefficient.

\subsubsection{Spatial resolution}

A high-speed IR camera (FLIR x6901sc) was used to observe the melt pool's cross section. The maximum resolution of the FLIR Indium Antimonide (InSb) detector was $640 \times 512$ pixels at a spectral range of 3.0-5.0 $\mu \mathrm{m}$ and a pixel pitch of $25 \mu \mathrm{m}$. For the experiments, a camera resolution of $96 \times 40$ pixels was chosen. To increase the
Table 2 Description of components in Fig. 3

\begin{tabular}{ll}
\hline Number & Name \\
\hline 1 & High-speed IR camera \\
2 & Protective glass for top view \\
3 & ZnS glass \\
4 & Height adjustment \\
5 & Glass ceramic \\
6 & Laser protective glass \\
7 & Pressure regulator for protective gas \\
8 & Building platform \\
9 & Recoater unit \\
10 & Overpressure valve \\
\hline
\end{tabular}

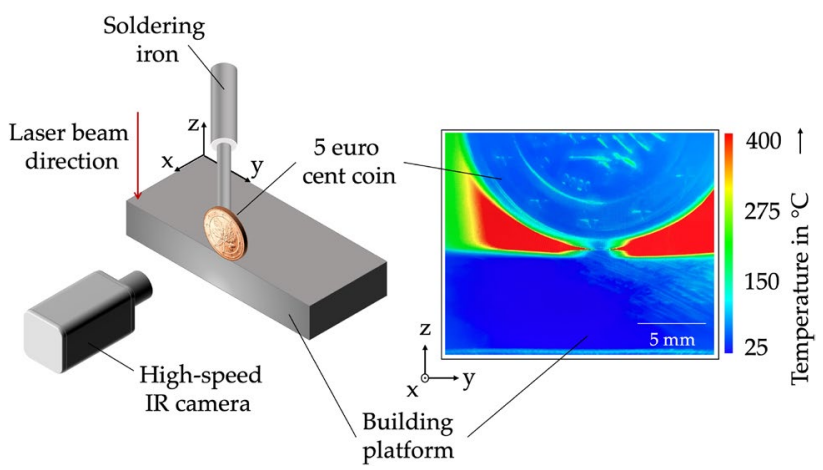

Fig. 4 Schematic of the set-up used to find the correct focal plane; the fine elevations of a standard euro cent coin made it suitable for adjusting the focus point of the camera

optical magnification, FLIR precision optics with a focal length of $100 \mathrm{~mm}$ and $68.5 \mathrm{~mm}$ long spacer rings were used. A maximum frame rate of $9762.5 \mathrm{~Hz}$ was achieved with the above resolution and hardware settings. Using the camera lens spacer with a total length of $68.5 \mathrm{~mm}$ reduced the object distance to $160 \mathrm{~mm}$. As it was a customized configuration, no pixel size information was available from the manufacturer. To determine this, it was necessary to adjust the focus point of the camera to the process zone. To adjust the sharpness of the camera, a heated euro cent coin (Fig. 4) was used. The heating of the coin was done with a soldering iron.

For a detailed analysis of the melt pool geometry, it is crucial to precisely know the pixel size of the image. A glass gauge with a resolution of $100 \mu \mathrm{m}$ was used for this purpose. The glass gauge was placed in the chamber in the same position as the euro cent coin and a soldering iron was used as a heat source. Fig. 5 shows a thermogram of the glass gauge. The thermal radiation of the vacuum-metalized scale was observed with the high-speed IR camera. With a stripe width of $100 \mu \mathrm{m}$ and an image size of $1.6 \mathrm{~mm}$, a resulting pixel size of $17.6 \mu \mathrm{m}$ was calculated for the horizontal and the 


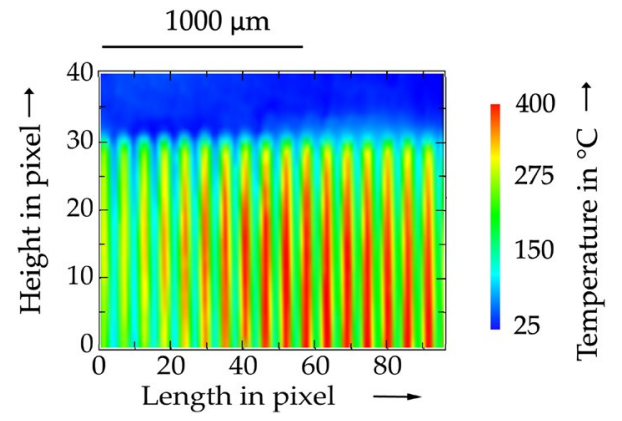

Fig. 5 Determination of the pixel size with a glass scale; due to the defined length of the scale and the different materials, the IR radiation could be distinguished which resulted in a pixel size of $17.6 \mu \mathrm{m}$
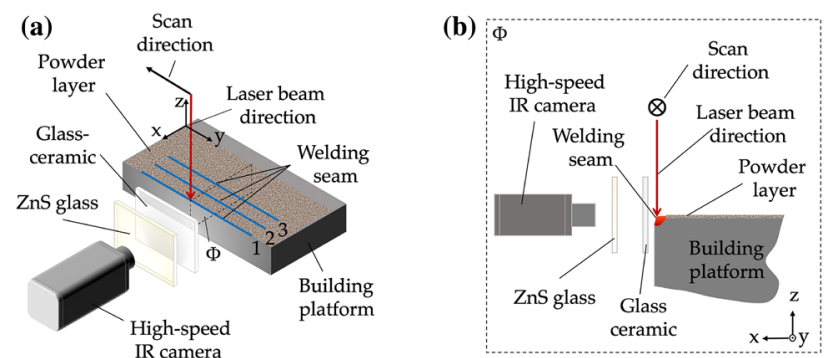

Fig. 6 Schematic diagram showing the laser path alignment in the PBF-LB/M chamber; the high-speed IR camera detects IR radiation from the process transmitted through a glass ceramic and a $\mathrm{ZnS}$ glass

vertical axes, with consideration of a quadratic pixel size at an orthogonal view.

\subsubsection{Scanning strategy}

To evaluate the influence of the powder additives on melt pool stability, the laser path was aligned in a way, so that the camera could observe the melt pool in the $z-y$ plane (Fig. 6). To do this, the laser path was shifted to the edge of the building platform. The high-speed IR camera was protected by a glass ceramic and a $\mathrm{ZnS}$ glass. The experiment involved exposing three lines, each with a length of $30 \mathrm{~mm}$, one at the edge of the building platform and two at a distance of $5 \mathrm{~mm}$ and $10 \mathrm{~mm}$ from the edge. The lines in the middle of the building platform serve as a comparison to the molten tracks at the edge in terms of width and depth.

A $39 \times 70 \times 8 \mathrm{~mm}$ plate made from $316 \mathrm{~L}$ was used as a substrate. The plate was precisely machined and sandblasted on the upper surface to provide a better hold for the powder particles during coating. A $20 \mu \mathrm{m}$ thick powder layer was then applied and the chamber closed and filled with argon 5.0. Fig. 7 shows an image of the building platform with the applied powder layer, (a) before laser exposure, and (b) afterwards with the solidified tracks.

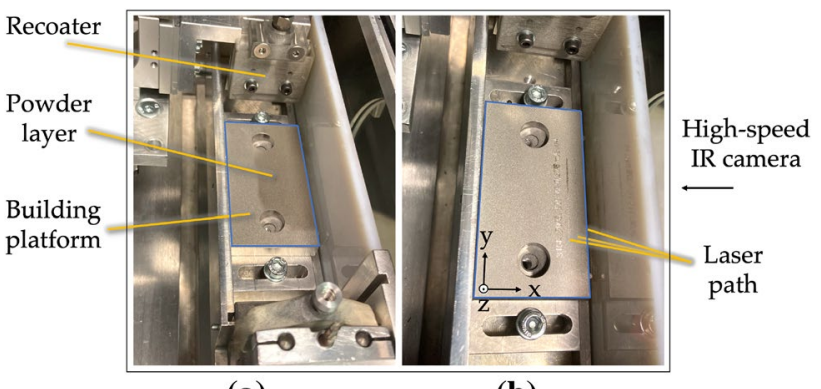

(a)

(b)

Fig. 7 Image of the building platform with applied powder layer: a before laser exposure and $\mathbf{b}$ afterwards with the solidified tracks

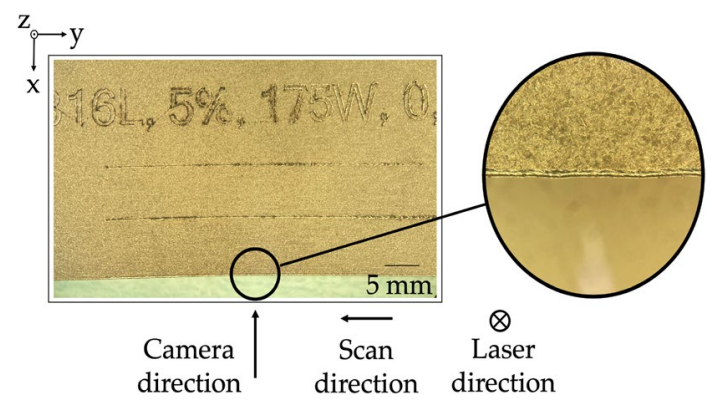

Fig. 8 Image of the solidified tracks taken with a stereo microscope; the detail image shows a uniform solidified track at the edge of the building platform without any balling or incomplete-fusion defects

Fig. 8 shows a stereo microscope image of the solidified tracks. The detail image suggests that the solidified track at the edge is very similar to a solidified track in the middle of the build platform, as it is uniform and without any noticeable balling or incomplete-fusion defects.

\subsubsection{Image processing}

At the chosen scanning speed of $0.375 \mathrm{~m} / \mathrm{s}$ and with a frame rate of $9762.53 \mathrm{~Hz}$, the melt pool appeared on about 70 frames. To determine the temperature of the phase transition with a high level of precision, ten representative images were selected on which the phase transition in the cooling curve was evident in great detail. The temperature of the phase transition was averaged and used as a representative temperature $T_{\text {rep }}$ for further evaluation. Fig. 9 shows an exemplary image for determining $T_{\text {rep }}$.

To evaluate the frames, a MATLAB code based on [18] was extended. The first step consisted of locating the pixel with the highest temperature. An evaluation line was then drawn through this point. The depth was measured from the surface to the deepest point of the melt pool. The column containing the evaluation line was written in a matrix as a new row. Each row belonged to one temperature curve in the vertical direction through the melt pool. A measuring 

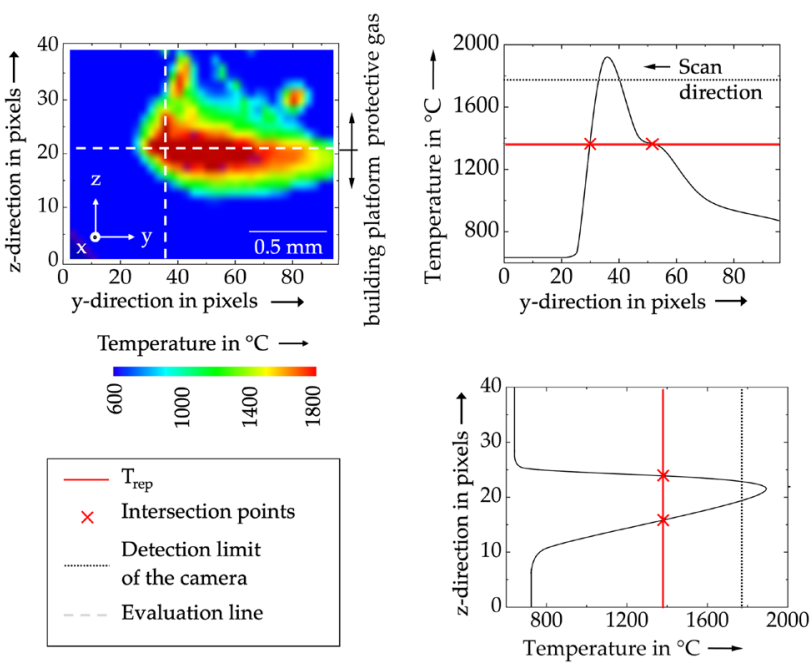

Fig. 9 Thermographic image of the melt pool in the cross section; the evaluation line depicts the horizontal and vertical temperature profile of the melt pool. The higher number of pixels in the horizontal direction means that the phase transition could be determined with higher precision than in the vertical direction. The representative temperature $T_{\text {rep }}$ is used for further evaluation of the melt pool depth

line was then created at the temperature $T_{\text {rep }}$. The next step involved determining the intersection between the measuring line and the temperature curves for each row. The intersection points are marked in Fig. 9 with a red cross. The distance between the intersection points was assigned to the depth of the melt pool, because the points represent the borders of the melt pool. The distance was calculated from the camera's determined pixel size.

\section{Results}

The weld seams on the edge and in the middle of the building platform were analyzed with micrographs (Fig. 10). All micrographs in this paper were ground with a Buehler

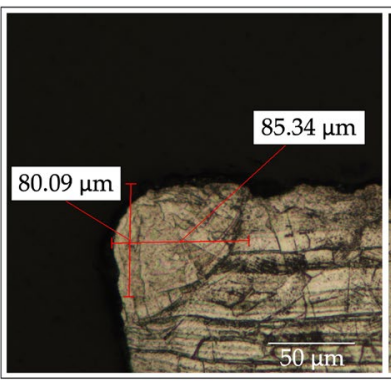

(a)

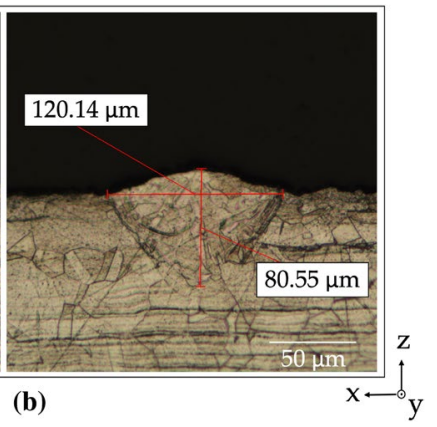

(b)
EcoMet 300 Pro device. Details of the grinding, polishing, and etching parameters can be found in Appendix A. The random images of the single melt tracks with $316 \mathrm{~L}$ powder show that the melt pool width varies between the weld seams on the edge of the building platform and those in the middle. However, the melt pool depth of the weld seam on the border is approximately the same as the one in the middle. This information is required so as not to overestimate or underestimate the melt pool depth by orders of magnitude with the thermographic image processing.

Figure 11 presents a selection of IR-images of the $1 \mathrm{wt} . \%$ blend. Here, every fifth frame was selected and arranged according to the respective process time. All frames are oriented with the scan direction in the negative y-direction. The high spots of the temperature curve above and below the flat spot are considered as spatter erupting from the melt pool. This is assumed to be exclusively hot spatter. Unmelted powder particles which become stirred up due to process gas flows remain undetected owing to their low temperature. Because of the nature of the experimental set-up, spatter can fall down between the building platform and the glass ceramic. For this reason, spatter beneath the building platform's surface was also recorded.

The thermographic images were evaluated using the image processing method referred to above. The melt pool depth in dependency of the AlSil0Mg content in wt.\% is shown in Fig. 12. The data show high agreement with the normal distributions. So it can be assumed that no systematic errors contributed to the data. The mean values range between $80.2 \mu \mathrm{m}$ for $316 \mathrm{~L}$ and $89.9 \mu \mathrm{m}$ for $316 \mathrm{~L}+20 \mathrm{wt} . \%$ AlSi10Mg and show a dependency on the AlSi10Mg content. This behavior is expected due to the higher laser

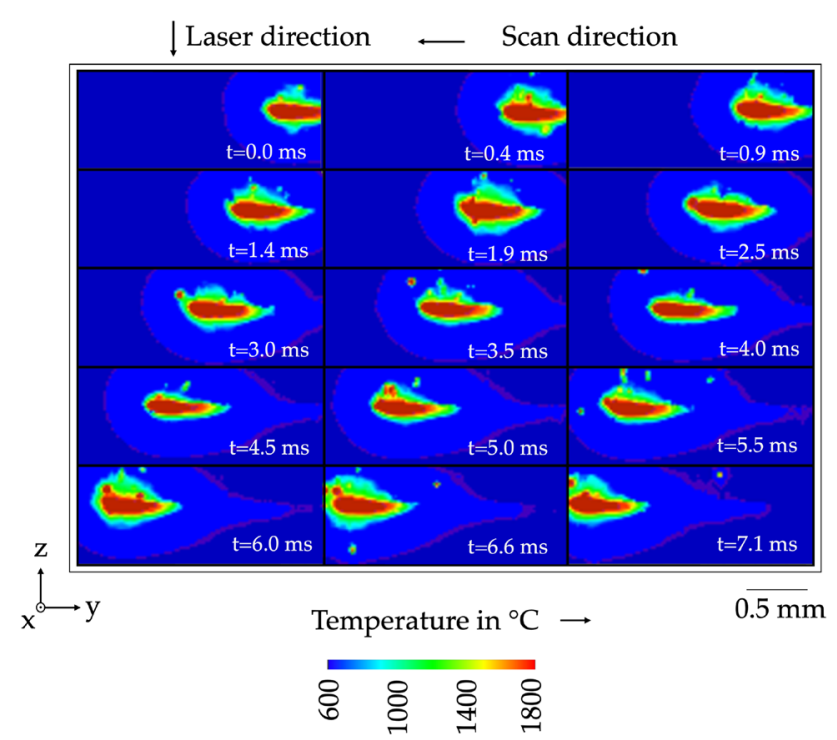

Fig. 11 Selection of IR images for $316 \mathrm{~L}$ powder blended with 1 wt.\% AlSi10Mg
Fig. 10 Cross section of the weld seams $\mathbf{a}$ on the edge and $\mathbf{b}$ in the middle of the building platform. The weld seams show similar depths, but the width varies 


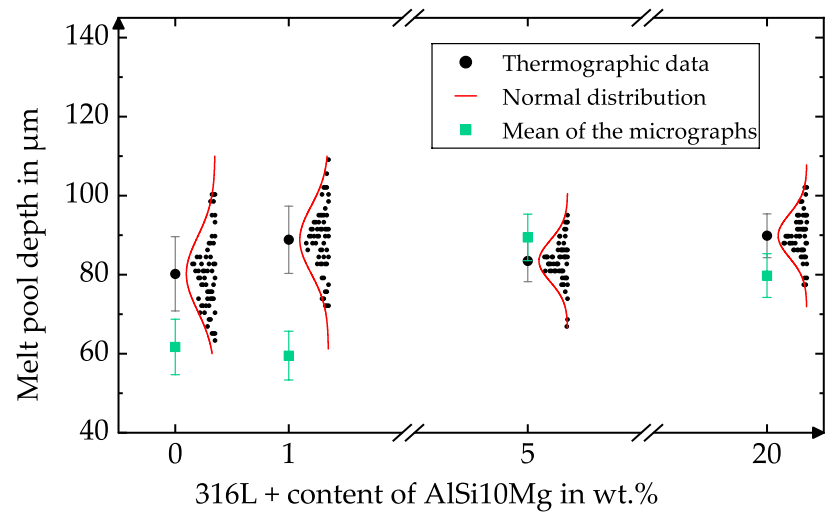

Fig. 12 Comparison of the melt pool depth in relation to the AlSi10Mg content; in the thermographic investigations, 63 frames were used for $0 \mathrm{wt} . \%, 59$ frames for $1 \mathrm{wt} . \%, 64$ frames for $5 \mathrm{wt} . \%$, and 62 frames for $20 \mathrm{wt} . \%$. The numbers differ because the melt pool images had to be filtered out where the melt pool was not completely visible on the image. The results of the micrographs are shown in addition to the thermographic data. The error bars indicate the relative standard deviation (all single micrographs can be found in "Appendix")

absorptivity of Si compared to the 316L base powder [19]. Therefore, a higher Si content in the powder blend results in a higher absorptivity and, thus, in a deeper melt pool.

In addition to that, the width of the distribution (relative standard deviation) decreases as the AlSi10Mg content increases. To analyze the quantitative change in the normal distribution, the relative standard deviations were calculated. This yielded a $48 \%$ smaller relative standard deviation for the $316 \mathrm{~L}+20 \mathrm{wt} . \%$ AlSi10Mg powder blend than for the $316 \mathrm{~L}$ without additives. As a measure of the melt pool stability, the change in width (rel. standard deviation) indicates that an AlSi10Mg content above $5 \mathrm{wt}$ \% significantly changes the melt pool dynamics and leads to a more stable melt pool.

The AlSi10Mg additives most likely affect the surface tension of the melt pool. The different surface tension coefficients of AlSi10Mg and 316L decrease the joint surface tension and may therefore reduce the Marangoni convection, which most probably stabilizes the melt pool. Wimmer et al. [13] showed that adding aluminum to $316 \mathrm{~L}$ powder alters the temperature gradient of the molten track. They observed smaller temperature gradients with higher amounts of aluminum. This observation is consistent with the assumption that the Marangoni convection is reduced since smaller temperature gradients lead to a smaller Marangoni convection. However, the low vaporization point of aluminum is increasing the recoil pressure which also affects the melt pool stability. The results of this work show that the effect of aluminum vaporization may play a subordinate role in this experiment. However, it is not yet clear to what extent the diffusion of the additive into the base material plays a role and how it influences physical properties like surface tension or heat conduction.

To validate the in situ measuring and evaluation principle, ex situ micrographs of the solidified tracks were conducted. The tracks are identical to those observed by the thermographic camera. The data is presented in Fig. 12 to enable a comparison with the thermographic data. It can be seen that the trend of the melt pool stability is also valid for the ex situ experiments, due to the decrease in relative standard deviation with increasing AlSi10Mg content. However, the mean melt pool depth displays a difference between in situ and ex situ data for $0 \mathrm{wt} . \%$ and 1 wt.\% AlSi10Mg. This might be explained by the different spatial resolutions of both sets of data. While the data for the in situ experiments were obtained over a length of approx. $1 \mathrm{~mm}$, the data for the micrographs were obtained over a length of approx. $20 \mathrm{~mm}$. The latter one is due to sawing and subsequent grinding processes which remove material. Several micrographs are necessary to ensure statistically meaningful results.

In the PBF-LB/M process, it is particularly important that investigations are performed on the smallest possible scale, since the numerous disturbance variables, such as a shifting beam diameter, a diverging powder layer thickness, or a differing process gas flow, may lead to variations in the experimental results. This is a major motivation for placing more trust in experiments conducted on a small spatial scale.

\section{Conclusions}

This study provides a methodology to systematically analyze the melt pool depth during PBF-LB/M. The methodology was used to investigate the melt pool stability for different powder blends. The main findings of this study are summarized in the following:

- In contrast to conventional PBF-LB/M machines, the experimental set-up presented here is suitable to observe the melt pool's cross section during PBF-LB/M.

- The melt pool's depth was determined by high-speed thermographic imaging and an optimized evaluation algorithm without dependence on the emission coefficient was proven to be suitable.

- The capability of the methodology was demonstrated for in situ alloying of $316 \mathrm{~L}$ powder blended with $\mathrm{AlSi} 10 \mathrm{Mg}$ 


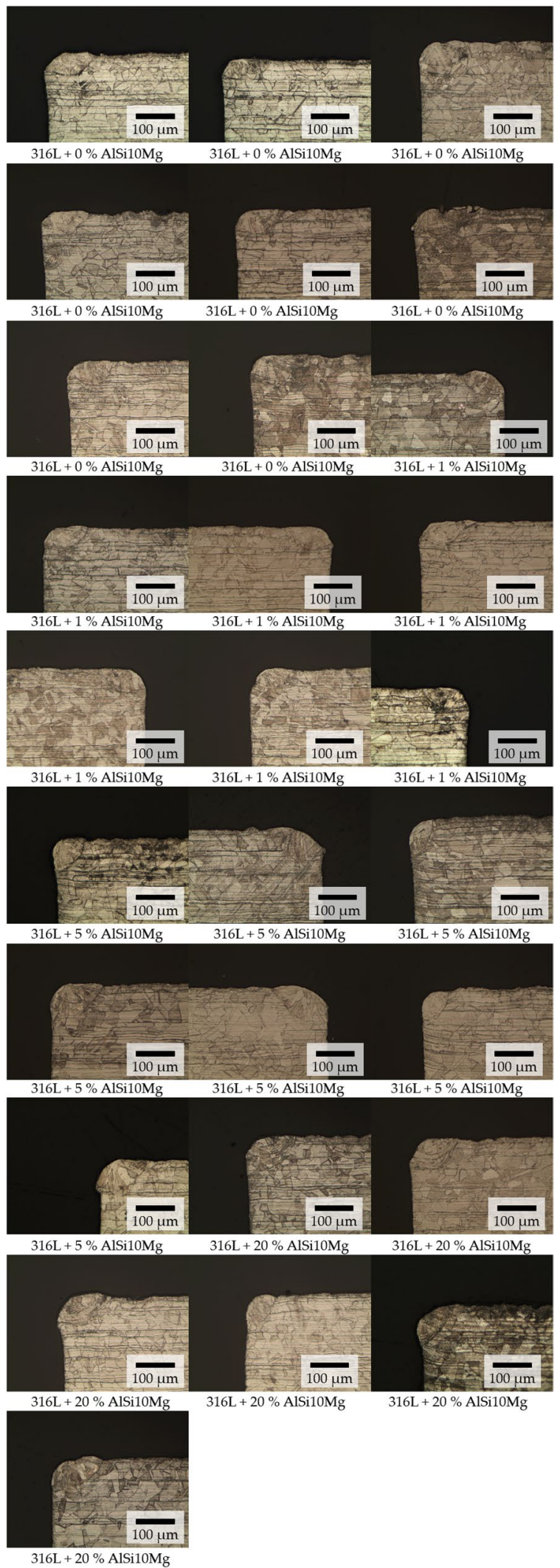

Fig. 13 Micrographs of the weld seams at the edge of the building platform for the different powder blends powder. The variation of the melt pool depth was $48 \%$ lower for the $316 \mathrm{~L}+20 \mathrm{wt} . \%$ AlSi10Mg compared to $316 \mathrm{~L}$ powder with no additives.

- The results indicate that the Marangoni convection may play a major role for the melt pool stability in this experiment while the recoil pressure plays a subordinate role.

Future investigations using this set-up could also include spatter tracking or the use of other powder blends. An analysis on the part level would also be of interest. The cross-sectional view enables temperature gradients over the whole part to determined during the PBF-LB/M process. This might provide understanding of heat accumulation processes which leads to part failure. The data could also be used for calibration or validation of a process or a structure simulation.

\section{Appendix}

Figure 13, Tables 3, 4, 5 .

Table 3 Polishing parameters

\begin{tabular}{lllll}
\hline Cloth & $\begin{array}{l}\text { Grain size } \\
\text { in } \mu \mathrm{m}\end{array}$ & $\begin{array}{l}\text { Rot. speed } \\
\text { in rpm }\end{array}$ & $\begin{array}{l}\text { Time } \\
\text { in min. }\end{array}$ & Liquid \\
\hline DP Mol & 3 & 150 & 30 & Lubr. blue \\
DP Nap & 1 & 150 & 25 & Lubr. pink \\
\hline
\end{tabular}

Table 4 Grinding parameters

\begin{tabular}{lllll}
\hline Sand paper & Granulation & $\begin{array}{l}\text { Rot. speed } \\
\text { in rpm }\end{array}$ & $\begin{array}{l}\text { Time } \\
\text { in min. }\end{array}$ & Liquid \\
\hline $\mathrm{SiC}$ & 180 & 300 & 30 & $\mathrm{H}_{2} \mathrm{O}$ \\
$\mathrm{SiC}$ & 360 & 300 & 30 & $\mathrm{H}_{2} \mathrm{O}$ \\
$\mathrm{SiC}$ & 600 & 300 & 30 & $\mathrm{H}_{2} \mathrm{O}$ \\
$\mathrm{SiC}$ & 2500 & 300 & 30 & $\mathrm{H}_{2} \mathrm{O}$ \\
\hline
\end{tabular}

Table 5 Etching parameters

\begin{tabular}{ll}
\hline Chemical & Amount \\
\hline $\mathrm{H}_{2} \mathrm{O}$ & $25 \mathrm{ml}$ \\
$\mathrm{HCl} 32 \%$ & $50 \mathrm{ml}$ \\
$\mathrm{FeCl}_{3}$ & $15 \mathrm{~g}$ \\
$\mathrm{ClCuH}_{4} \mathrm{~N}$ & $3 \mathrm{~g}$ \\
\hline
\end{tabular}


Funding Open Access funding enabled and organized by Projekt DEAL. This research was supported by the Deutsche Forschungsgemeinschaft (DFG) with the project number 387081806.

Availability of data and material The datasets generated during the current study are available from the corresponding author on reasonable request.

\section{Declarations}

Conflict of interest The authors declare that they have no conflict of interest.

\section{Code availability Not applicable}

Open Access This article is licensed under a Creative Commons Attribution 4.0 International License, which permits use, sharing, adaptation, distribution and reproduction in any medium or format, as long as you give appropriate credit to the original author(s) and the source, provide a link to the Creative Commons licence, and indicate if changes were made. The images or other third party material in this article are included in the article's Creative Commons licence, unless indicated otherwise in a credit line to the material. If material is not included in the article's Creative Commons licence and your intended use is not permitted by statutory regulation or exceeds the permitted use, you will need to obtain permission directly from the copyright holder. To view a copy of this licence, visit http://creativecommons.org/licenses/by/4.0/.

\section{References}

1. Lohmuller P, Favre J, Kenzari S, Piotrowski B, Peltier L, Laheurte $P$ (2019) Architectural effect on 3D elastic properties and anisotropy of cubic lattice structures. Mater Design 182:108059

2. Roca JB, Vaishnav P, Fuchs ERH, Morgan MG (2016) Policy needed for additive manufacturing. Nat Mater 15(8):815

3. Mukherjee T, Zuback JS, De A, DebRoy T (2016) Printability of alloys for additive manufacturing. Sci Rep 6(1):1

4. Cunningham R, Nicolas A, Madsen J, Fodran E, Anagnostou E, Sangid M, Rollett A (2017) Analyzing the effects of powder and post-processing on porosity and properties of electron beam melted Ti-6Al-4V. Mater Res Lett 5:1

5. Martin A, Calta N, Hammons J, Khairallah S, Nielsen M, Shuttlesworth R, Sinclair N, Matthews M, Jeffries J, Willey T, Lee J (2019) Ultrafast dynamics of laser-metal interactions in additive manufacturing alloys captured by in situ X-ray imaging. Mater Today Adv 1:100002

6. Zhao C, Fezzaa K, Cunningham RW, Wen H, De Carlo F, Chen L, Rollett AD, Sun T (2017) Real-time monitoring of laser powder bed fusion process using high-speed X-ray imaging and diffraction. Sci Rep 7(1):1
7. Fischer M, Joguet D, Robin G, Peltier L, Laheurte P (2016) In situ elaboration of a binary Ti-26Nb alloy by selective laser melting of elemental titanium and niobium mixed powders. Mater Sci Eng C $62: 852$

8. Montero-Sistiaga ML, Mertens R, Vrancken B, Wang X, van Hooreweder B, Kruth JP, van Humbeeck J (2016) Changing the alloy composition of Al7075 for better processability by selective laser melting. J Mater Process Technol 238:437

9. Martin JH, Yahata BD, Hundley JM, Mayer JA, Schaedler TA, Pollock TM (2017) 3D printing of high-strength aluminium alloys. Nature 549(7672):365

10. Zhai W, Zhu Z, Zhou W, Nai M, Wei J (2020) Selective laser melting of dispersed TiC particles strengthened 316L stainless steel. Compos Part B Eng 199:108291

11. Al-Mangour B, Baek MS, Grzesiak D, Lee KA (2017) Strengthening of stainless steel by titanium carbide addition and grain refinement during selective laser melting. Mater Sci Eng A 712:812

12. Zhao Z, Li J, Bai P, Qu H, Liang M, Liao H, Wu L, Huo P, Liu $\mathrm{H}$, Zhang J (2019) Microstructure and mechanical properties of TiC-reinforced 316L stainless steel composites fabricated using selective laser melting. Metals 9:267

13. Wimmer A, Kolb CG, Assi M, Favre J, Bachmann A, Fraczkiewicz A, Zaeh MF (2020) Investigations on the influence of adapted metal-based alloys on the process of laser beam melting. J Laser Appl 32(2):022029

14. Khairallah SA, Anderson AT, Rubenchik A, King WE (2016) Laser powder-bed fusion additive manufacturing: Physics of complex melt flow and formation mechanisms of pores, spatter, and denudation zones. Acta Materialia 108:36

15. Calta NP, Wang J, Kiss AM, Martin AA, Depond PJ, Guss GM, Thampy V, Fong AY, Weker JN, Stone KH, Tassone CJ, Kramer MJ, Toney MF, Van Buuren A, Matthews MJ (2018) An instrument for in situ time-resolved X-ray imaging and diffraction of laser powder bed fusion additive manufacturing processes. Rev Sci Instrum 89(5):055101

16. Labudovic M, Hu D, Kovacevic R (2003) A three dimensional model for direct laser metal powder deposition and rapid prototyping. J Mater Sci 38(1):35

17. Doubenskaia M, Zhirnov I, Teleshevskiy V, Bertrand P, Smurov I (2015) Determination of true temperature in selective laser melting of metal powder using infrared camera. Mater Sci Forum 834:93

18. Wimmer A, Lehmann M, Schuler A, Zaeh MF (2020) Analysis of the phase transformation of AlSi10Mg during laser powder bed fusion. Procedia CIRP 94:177

19. Aversa A, Moshiri M, Librera E, Hadi M, Marchese G, Manfredi D, Lorusso M, Calignano F, Biamino S, Lombardi M, Pavese M (2018) Single scan track analyses on aluminium based powders. J Mater Process Technol 255:17

Publisher's Note Springer Nature remains neutral with regard to jurisdictional claims in published maps and institutional affiliations. 